\title{
Towards a technology and agglomeration platform of the colombian caribbean shipyard sector
}

Hacia una plataforma tecnológica y de aglomeración del sector astillero del caribe colombiano

DOI: https://doi.org/10.25043/19098642.167

Jesús Alberto Villamil ${ }^{1}$

\begin{abstract}
The need to create the conditions to improve the productivity and competitiveness of the shipyard sector in the Caribbean Region, is framed by the greatest challenges and technological advances, especially in the adoption of technologies in the naval industry, which implies the making of investment decisions based on the development of research and development activities. Agglomeration (clusterization) trends tend to define articulating and animating agents that allow the establishment of a technological and competitiveness agenda (technological platform) for the adoption of a new model based on innovation and technological development. The world-wide experiences of the role of the generation of technologies are varied, not only from the private but also public scope for the improvement in competitiveness in the shipyard sector. In the Caribbean region, thanks to COTECMAR's trajectory, some of its capabilities could be oriented to define, on the one hand, the medium- and long-term strategy for the shipyard sector, and on the other, to establish a market and technology intelligence center and finally to define itself as an animator between the different public and private actors that lead to the development of important technology projects based on innovative processes of transfer and commercialization, without losing its mission of being a guarantor of National Security and Defense.
\end{abstract}

Key words: Shipyards; cluster; agglomeration; Technological platform.

\section{Resumen}

La necesidad de crear las condiciones para mejorar la productividad y competitividad del sector astillero en Colombia, se enmarca en los mayores desafíos y avances tecnológicos, especialmente en la adopción de tecnologías en la industria naval, lo que implica la toma de decisiones de inversión fundamentadas en el desarrollo de las actividades de investigación y desarrollo. Las tendencias de aglomeración (clusterización) pasan por definir agentes articuladores y animadores que permitan establecer una agenda tecnológica y de competitividad (plataforma tecnológica) para la adopción de un nuevo modelo sustentado en la innovación y el desarrollo tecnológico. Son variadas las experiencias a nivel mundial del papel que juega la generación de tecnologías, no solamente desde el ámbito privado sino público para la mejora competitiva en el sector astillero. En la región Caribe, gracias a la trayectoria de COTECMAR, podrían orientarse algunas de sus capacidades para definir de un lado la estrategia de mediano y largo plazo para el sector astillero, de otro establecer un centro de inteligencia de mercados y tecnologías y finalmente definirse como un animador entre los diferentes actores públicos y privados que conlleven al desarrollo de importantes proyectos de tecnologías sustentado en novedosos procesos de transferencia y comercialización, sin perder su misión de ser garante de la Seguridad y Defensa Nacional.

Palabras claves: Astilleros; clúster; aglomeración; plataforma tecnológica.

Date Received: February $28^{\text {th }} 2017$ - Fecha de recepción: Febrero 28 de 2017

Date Accepted: March 15 2017 - Fecha de aceptación: Marzo 15 de 2017

${ }^{1}$ Professor of Universidad Nacional of Colombia. Colombia. Email: javillamilm@unal.edu.co 


\section{Introduction}

The national industry that supports the maritime transport services sector in the Caribbean region has been evolving dynamically in recent years. On the one hand, the sector is being recognized as part of national and regional public policy. The actors that take part recognize their potential in terms of productivity and competitiveness. Likewise, the agents that guide regional development consider it as a strategic sector for economic and regional development. In this way, and bearing in mind that the maritime sector has had an evolutionary trajectory in the Caribbean region due to its close link to maritime and port activities, it is considered a viable alternative to guide collaborative and integrating strategies through agglomeration schemes (cluster).

Like much of the country's regional initiatives, the Caribbean region and its productive activity move between two simultaneous but converging forces: Globalization-Productive Specialization and Regionalization-Innovation. The first, in the framework of the maritime industry and port, the "ship building sector", particularly in the Caribbean region, has been gaining a leading role. It is part of the sectors of the policy of productive transformation that led by the Ministry of Industry, Trade and Tourism, sustained in the National Policy of Competitiveness in promotion of the productive transformation defined in world class sectors (DNP, 2008) ${ }^{1}$; and in the National Policy on Science, Technology and Innovation; (DNP, 2009). The second, the Caribbean Region and particularly the city of Cartagena and the Department of the Atlantic, they chose the maritime industry as a regional bet that aims to promote the productive apparatus articulating policy instruments of a regional nature especially in terms of Science, Technology and Innovation.

This article is intended to expose some guidelines on agglomeration schemes from international referents oriented by institutional arrangements at the local level or under regional schemes derived from public policies. For the definition

\footnotetext{
I National Planning Department, Conpes Document 3527, National Competitiveness and Productivity policy, Bogotá June 2008.
}

of an animation model that integrates knowledge networks and the definition of the Cluster, some of the conditions in terms of scientific and technological capacities to be identified are the guidelines embodied in the research agendas and the presence of COTECMAR at the regional level. Priority elements justifying an intervention to propose an induced system of agglomeration and collaborative work at local and territorial level in accordance with the region's productive structure.

The strategic orientation of the shipyard sector must go through a strategic plan of organization and institutional arrangements, which lead to the creation of agglomeration schemes based on $\mathrm{R}+\mathrm{D}$ + I activities, where the State has a decisive role when it comes to concreting incentives. The application of these "incentives" leads to the realization of the orientation, making the cyclical and structural determinants of the maritime and port industry visible. It also induces the recognition of cooperation schemes supported in the relationships and scientific and technological capacities as an instrument to support technological innovation of the shipyard sector in the Caribbean region. Its origin, the role of the agents, companies and institutions that make it up; and how the concept of knowledge management is incorporated is highlighted.

The first part of the text describes some conceptual aspects on the basis of the agglomeration schemes and some actions that guide the innovation (achieving better levels of productivity and competitiveness) and innovative means for the regional development. The second part describes the scope and limits of the shipyard sector's agglomeration scheme within the framework of the naval industry of the Caribbean region. and finally, without, without prejudice to other evidence, some paths are defined to consider the technological platform of the shipyard sector of the Caribbean region to promote development from innovation management models.

\section{Conceptual Aspects}

Recently, the country has entered into the public policy debate on the desirability of 
driving economic regional development from the participation of actors at the local level. This discussion, which starts in large part due to the promotion of the productive bets and competitive strategies (Internal Agenda for Productivity and Competitiveness-DNP 2008-) and that has been gathering strength in the framework of the national policy on productive development and the guidelines of the national policy of Science Technology and Innovation in the country.

A greater self-determination in the decisions of the actors (companies and universities) located in certain territories and with influence in local agencies (e.g. chambers of commerce, municipalities, guilds and associations among others) starts by recognizing agglomerated productive structures that beyond their spatial location, seek to orient and create schemes for cooperation and knowledge management for economic and social development, improvements in productivity and competitiveness of the actors that are part of the productive systems.

The study of the phenomena of agglomeration and location of productive activities has a great theoretical tradition that is based on the pioneering works of the classical economy from the division of labor and the configuration of the territories. Marshall (1890), who begins with the division of labor as a condition of relationships between companies and the conception of a territory where these relations are developed in a context of interaction and learning. Coase (1937 and 1988) ${ }^{2}$ realizes the significance of the vertical integration processes in defining the links that are derived in the relationships between agents and that explain the transaction costs to support the neo-institutional framework of the nature of the company. In the eighties a series of literature appeared to understand the relationships and connections between the agents in different productive systems and the reasons for the coexistence of the actors.

Michel Wear, in the year 1991, advanced with the concept of clusters (Saba 2003) and evaluated the

2 In Willianson O and Signey G. Winter. The nature of the company. Origin, evolution and development. Economic Culture Fund. Mexico 1996. management conditions of the industrial districts, (Texerira and Ferraro, 2009) address the relations and management schemes in value chains. In the framework of the competitiveness policies of several European countries, expressions like the competitiveness and innovation poles associated with a sector in a certain territory appear. These approaches, notwithstanding their different approaches from the degrees of development and participation of different actors, they share some features such as knowledge management and collective learning.

An agglomeration scheme (cluster) is the recognition of different actors with common characteristics in certain productive systems (static and dynamic links), with cultural and family relations, located in certain territories. Some of these agglomeration schemes have been induced by congruence in the public and private institutional relations that have been able to create spaces that identifies them as efficient and competitive productive structures. Therefore, a cluster (a grouping) facilitates the generation and dissemination of knowledge that is both tacit and explicit expressed in transfer and appropriation processes, which determine decisions or strategic actions.

A cluster, according to Michael Porter (1998), is a geographic concentration of interconnected companies, specialized suppliers, service providers, companies in related industries, and partner institutions in competing private fields but they also cooperate. According to Porter, the success of a cluster includes the organization of factors based on the conditions associated with four elements: demand, production factors, development and competition strategies and to the development of complementary industries. These groupings seek to obtain advantages such as:

- Better dissemination of information and a reduction in costs related to the coordination of agents.

- Increased productivity of cluster-owned enterprises.

- An innovation boost.

- Stimulus for the creation of new companies in the subject matter of the cluster (logistics, aerospace, automotive, etc.). 
At present the configuration of the different agglomeration (cluster) initiatives are based on the role that the management of scientific and technological knowledge plays. In this context it becomes important how knowledge is created and used; and how individual and group capacities are developed to generate, disseminate and use it. Empirical evidence of the relationship between technological development and economic growth is growing every day, as is the importance of technology as engine of the innovation in construction and improvement of regional competitiveness based on a greater cohesion of local actors.

An agglomeration figure comprising $\mathrm{R}+\mathrm{D}+\mathrm{I}$ activities for productive strengthening is based on the conception of the national innovation systems studied throughout history by Freeman $(1997)^{3}$ as a network of public and private institutions whose activities and interactions initiate, import, modify and disseminate new technologies and that are driven by economic and social policies. Lundvall $(2005)^{4}$ considers a national innovation system as a set of elements and relationships that interact in the production, dissemination and use of new and useful knowledge for its economic leverage, located in a specific region. Metcalfe, $(1995)^{5}$ emphasizes the nature of this interaction by considering that this contributes to the development and diffusion of new technologies, context in which, the intervention of the State is required in designing and executing policies that stimulate the processes of innovation.

The cluster initiatives based on innovation and cooperation as Key elements means having a critical concentration of resources in a geographical place, where collaboration is prevalent from three types of actors: companies, universities and regional/local authorities. The State (represented in the regional

\footnotetext{
3 Freeman C and Luc Soete National System of Innovation. The economics of industrial Innovation Third Edition 1997- The MIT Press.

$4 \quad$ National Innovation Systems - Analytical Concept and Development Tool by Bengt-Åke Lundvall 2005. Paper presented at the DRUID-conference in Copenhagen June 27- June 29, 2005. 5 Metcalfe, J. S. (1995). The economic foundations of technology policy: equilibrium and evolutionary perspectives. In $\mathrm{P}$. Stoneman (Ed.), Handbook of the Economics of Innovations and Technological Change. Oxford: Blackwell Publishers.
}

agencies) establishes environment conditions that guarantee and facilitate the actions of the productive sector. Thus, it will be possible to encourage and promote the use of the knowledge generated by the scientific research in the productive processes, to channel financial resources for the development of the scientific and technological infrastructure, to orient the efforts for the productive improvement, especially in favour of added value and innovative capacity, all to achieve competitive conditions in the market.

It should be noted that cluster initiatives based on activities of research, development and innovation are based on the novel concept of open innovation, proposed by Henry Chesbrough $(2003)^{6}$ to promote relationships to maximize the generation of knowledge, information, capacities and skills in collaborative schemes. This concept goes against traditional schemes of innovation (closed), propitiated by departments of R\&D of companies according to their own capacities, knowledge and schemes. Open innovation allows to capacities and knowledge to be optimized and has the potential to accelerate work dynamics, the understanding of joint needs and the distribution of ownership for the obtained developments.

Much of the development of industrialized countries in the last 30 years is explained by the close relationship between scientific and technological research and innovation. The majority of the transformations of the most advanced productive structures are recognized by the capacity of generation and appropriation of knowledge of companies, thanks to the development of the policies of science, technology and innovation, in creating spaces to encourage work in a network among researchers and entrepreneurs. The generation of new knowledge that allows innovation and technological development are effective tools in the creation of regional competitive advantages (Innovación Europea 1995) ${ }^{7}$.

\footnotetext{
Chesbrough (2003), The Era of Open Innovation. Spring MIT Sloan Management Review.

7 Innovación Europea ("European Innovation") (1995), More research and innovation. Investing for growth: a Common approach. European Commission, Brussels Belgium.
} 
In the development of agglomeration strategies (Cluster), there is a wide variety of sources and actors generating knowledge. In companies there are $\mathrm{R} \& \mathrm{D}$ units, groups, specialized departments of quality, design and marketing. In its environment, business initiatives are supported by public entities, R\&D centers, universities, technological development centers, research and excellence centers, consumers, etc. Notwithstanding the wide variety of sources and actors, successful countries are characterized by channeling major public resources through regional (local) science, technology and innovation systems that have led to the development of long-term strategies and with a competitive and market guidance. A demonstration are the regional innovation poles that guide their efforts in key sectors (strategic or export oriented) for competitiveness in the framework of the regional initiatives driven by the European Union (Innovación Europea, 2006 and 2007).

A successful approximation of agglomeration schemas are the successful practices that have been consolidated globally in the territorial development represented by the Italian industrial districts, or the agglomeration schemes of Silicone Valley and the Triangle Park in the United States, Glenn Valley in Scotland, the Inshu park in Taiwan, etc., and in the schemes encouraged by recent European policies to consolidate competitiveness poles and innovation.

\section{Scope and limits of the agglomera- tion scheme of the shipyard sector that supports the naval industry}

The Regional Competitiveness Plan of Cartagena and Bolívar (2008-2032) -PRCCB 2010contemplates the design, construction and repair industry of ships as a driver of the local economy ${ }^{8}$. In this way it defines as a strategic objective to "internationally consolidate the naval, maritime and fluvial cluster of Cartagena and Bolívar aimed at providing technology solutions integrated to the design, construction and repair industry of boats", where the internationalization of this sector is

\footnotetext{
Regional Competitiveness Commission of Cartagena and Bolívar. (2010). Regional competitiveness Plan Cartagena and Bolívar 2008 - 2032.
}

projected and the consolidation of a cluster with great potential that would allow the economic development of the Caribbean region.

Starting from the recognition of the actors who are part of the maritime and fluvial industry, agglomeration initiatives have been configured to strengthen the productive development of the ship yard sector in the Caribbean region led by the PTP of MICT and the impulse that has been given to the services that support the nautical cluster: Nautical Cartagena'. This approach aims to promote in regional actors the management and strengthening of links that promote collaborative strategies aimed at developing new changes, promoting research, development, innovation and stimulating the entrepreneurship of new technology-based companies.

Setting the limits of the cluster is not an easy task and usually requires a process of animation and definition to determine the relations and links of complementarity between the sectors and institutions to participate. From the definition of the cluster of the shipyard sector we pass to recognize the maritime transport sector and the port environment where a set of activities are performed with different actors. Activities include business, industrial and logistics activities, among the sea and nautical transport customers: the cargo of merchandise, passengers, and all the agents of the zone of influence of the ports, the free zones and the maritime enclaves as well as the new development of marinas.

Specifically, as defined by the PRCCB 2010, Cartagena has an excellent geographical position, natural conditions of depth and protection of

\footnotetext{
9 The Cartagena nautical cluster includes companies dedicated to the production of boats (emphasize that production is marginal), particularly fiber boats with outboard motor with a maximum length of 6-8 meters, supplying nautical accessories such as outboard motors, electro-electronic equipment, metalworking parts and structures, painting, among others, and equipment for nautical sports activities (diving, Kitesurfing, windsurfing, kayaking, etc.); As well as the management and development of marinas., dry marinas and MAVs (Marina-Shipyard-Varadero), including services to the boat (mooring, storage, fuel load, repair and minor maintenance). There is also an important offer of complementary tourist services such as lodging, food, commerce, among others. Competitiveness, Nautical Cartagena: Competitive route of the nautical Industry 2015
} 
Fig. 1. Cluster Map in Cartagena

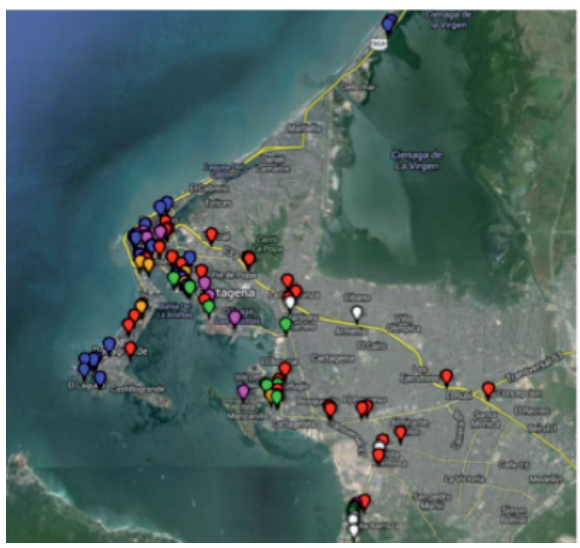

Suppliers

Phipyards

Marine

Boat dealers and intermediaries

Complementary

offer

Government and support entities

the bay, human resources that are qualified and trained for the care of vessels up to 600 tonnes, an adequate infrastructure and canal of 3,600 tons per boat. In 2016 the shipyard sector that is part of the cluster had more than 70 actors that are part of the shipyard sector, $85 \%$ of the ship building activity is located in Cartagena with more than 3000 workers. Cartagena is recognized for its military and commercial shipyards, highlighting the leading role of Cotecmar at the forefront of research and development activities ${ }^{10}$.

On the other hand, as shown in Competitiveness 2015, Cartagena is one of the ports with the greatest historical weight of the Caribbean. It is the most important port in Colombia in the area of container loading and also in cruise tourism, which means it has a naval and nautical vocation. In Cartagena nautical tourism has witnessed a notable development, and in the bay area there are several facilities for recreational boats, which have joined shipyards located in other parts of the city, such as in Albornoz and el Bosque, complementing the offer of services required by boat owners, such as yachts and sailboats (See Fig. 1).

Like the corporate management models, the coherence of decisions and actions taken by the different cluster actors are essential to establishing common strategic guidelines and sharing performance criteria. What's more, the guidelines,

10 Regional Competitiveness Commission of Cartagena and Bolívar. (2010). Page 36. plans, which currently orient the shipyard sector cluster have to be developed around a specific purpose, be it of broad connotations like the development with the maritime and naval industry, or a specific geographical area (the city of Cartagena and the Department of Atlántico and Bolívar for example) or more focused like the solution of a technical problem such as the support services to the naval and port industry through the shipyard sector.

It is necessary to define the scope and limits of an agglomeration scheme for the shipyard sector within the framework of the maritime transport sector and the naval industry, where actors are identified that have characteristics and particularities that must be taken into account in order to achieve certain development and growth objectives in the short and medium term, as established by Ospina $(2016)^{11}$ based on what is defined by Untcad 2015 as follows:

- Maritime transport plays a crucial role in defining the benefits that ships must develop as it identifies those improvements and innovations that will need to be implemented in ships and artifacts, in order to be able to improve the processes of design, construction, operation and logistics management.

- The infrastructure, port management activity and port services are major sectors in the

\footnotetext{
1 Ospina, Juan C, Ideas for a reflection on maritime transport in Colombia, in La Timona magazine No 25 June 2016.
} 
transport logistics chain, key elements for intermodality and consequent promotion of maritime transport as an alternative or complementarity to other types of transport.

- The Exploitation of marine resources through platforms or artifacts dedicated to the exploitation of mineral resources, hydrocarbons and fisheries, aquaculture and other resources of the sea, is an element essential for obtaining these resources from diversified origins in relation to their traditional sources. In addition it involves production in water away from the coast, that are ultra-deep or in arctic regions.

- The design, construction, transformation and repair of all types of ships, Naval platforms and artifacts, including off-shore industry and nautical and recreational needs, they need to respond to the ever more complex demand for ships that are more sophisticated, more secure and more respectful of the environment and that require, therefore, a more developed technology; and all of this with lower operating and maintenance costs.

- The activities of the auxiliary industry and services have an increasing importance in the total value of the vessel, and may even reach three quarters of the final value. The number of companies with national capital that compete successfully in this sector with their own technologies in an open and truly globalized international market is remarkable, offering its customers the solutions that allow them to respond to the demand of technologically innovative vessels.

Particularly as defined by the MINCIT the shipyard cluster sector includes activities oriented

Fig. 2. Map of Actors - Shipyard Sector Cluster

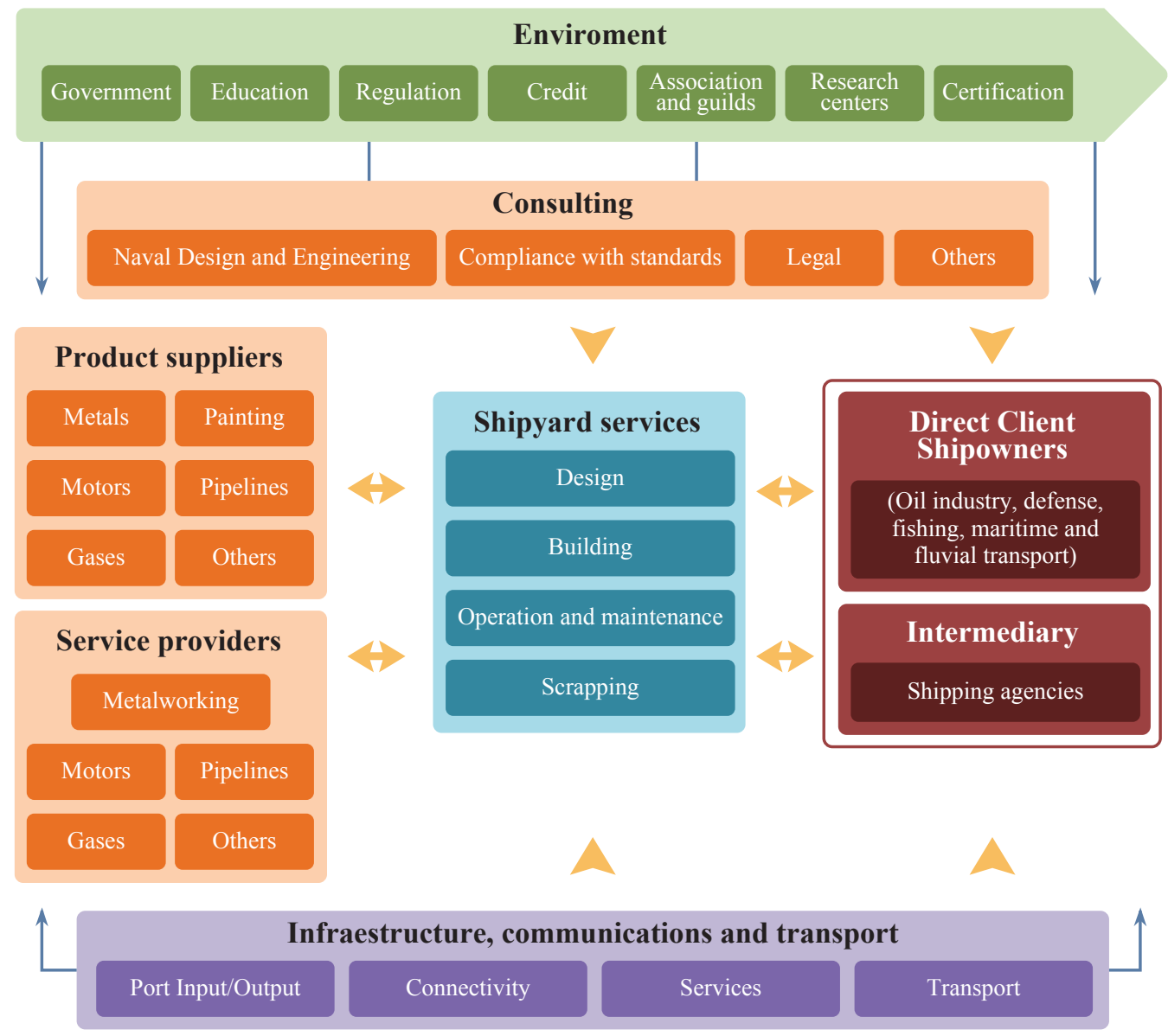


to the services of repair and construction of boats in an integrated way with the maritime and port industry located in the Caribbean region. This is illustrated by the map of actors defined by the PTP-MINCIT.

Thus, a broad definition of a maritime cluster would also include logistical and transport activities ${ }^{12}$, for the case of the cluster of the shipyards sector in the Caribbean region it would be:

The shipyards, will be the axis, which includes the companies that build and repair ships (with steel and other materials such as wood) of very diverse types and tonnages, for the transport of goods and passengers or for military use.

Suppliers of inputs and services: companies dedicated to the supply of equipment and naval services that include:

- Companies whose activity is aimed at providing service to shipyards, such as submarine work, enabling, integral services, welding, boiler making, scaffolding, paint applicators, assemblies, cleaning, anti-corrosion protection, electronics, electricity, etc.

- Also included are design companies of boats and engineering (Mechanics, electronics, surface treatment) and technical offices.

- Companies whose activity is focused on the provision of the equipment that make up the engine room of a ship. It is usually divided into 2 main groups:

- Engines

- Auxiliary equipment of machines: Pumps, alternators, advanced systems of dieselElectrical propulsion, electrical and control panels, cooling and ventilation, insulation, valves, onboard automation systems, electronics, electricity, etc.

- Supply of artifacts for the hull or deck of

12 From the definition defined by Valdaliso Gago [et al.]. The historical origins of the maritime industry cluster in the Basque Country and its legacy for the present/Jesus-Donostia: Eusko Ikaskuntza; Orkestra. Basque Institute of Competitiveness, 2010 Pages 72 and 73. ships, such as cables, pipes, chains, electronics, electricity, insulation, hydraulics, structural elements, hoisting equipment, capstans, etc.

- In the nautical activity, companies that offer the service of design, construction, sale/distribution and repair of different products are recognized. Equipment and materials: related more to the equipment of the boats such as: engines, transmissions or communication mechanisms, parts of the boat, masts, rafts, emergency signals, electromechanical mechanisms, painting, resins, wood, carpentry, etc., as well as the supply of accessories: holsters, nets, log clocks, ropes, life jackets, and other boat accessories.

- Other companies that offer inputs such as: Oils, fuels, and the whole range of detergents and cleaners, etc.

\section{Of a technological platform towards an agglomeration of the shipyard sector}

The National Policy of Science, Technology and Innovation, expresses the need to strengthen and design new instruments, by strengthening innovation and productivity in companies and organizations, with the aim of ensuring in the long term the competitiveness of national and regional production goods and services; and to improve the living conditions of the Colombian population $(\text { DNP-2009) })^{13}$.

These new conditions of the economic environment, together with the greater requirements of the global consumers and the new ways of doing business, impose on the companies the challenge of modernizing their organizational structure and, even more so, to innovate in their processes, products, goods and/or services, their offer of value and their business model, all for the purpose of achieving greater competitiveness. The

\footnotetext{
13 National Planning Department. National policy on science, technology and innovation. Document Conpes No. 3582. Bogotá, April 2009.
} 
modernization and business innovation process is complex because it not only obeys the internal conditions of each company, but also the conditions of their economic and social environment, and the close relationship between the capacities of the companies and those associated with local scientific and technological capacities.

In the country, there is a belief that the agglomeration schemes (cluster) per se are beneficial for innovation and local development. In reality experience has shown that very little is known about what they mean and really of how they operate. There is a tendency to implement policies to support the clusters without defining actors and limiting the actions and roles. many of the initiatives are not defined as such and usually support policies and promotion to the cluster are confused with the instruments of the national public policies of productive development and innovation. The support instruments for the clusters, are usually not very novel, but what is new is the form of the combination of instruments that is chosen and appropriate by direct actors. Therefore, the challenge that is posed to the local actors is to find the ideal combination of tools.

The local and regional authorities should have the best conditions to adopt the support policies for the cluster given its proximity to the companies. A directed cluster support policy is not possible and even less so if management is oriented using the generic instruments defined by the government entities. A good identification of the relationships of the clusters contributes to the elimination of administrative barriers (red tape) that usually limit public aid. A cluster needs some type of geographical settlement, proximity is essential, despite the progress of communications, this is necessary to guarantee the transfer and appropriation of knowledge that supports the degree of local innovation.

A successful cluster is that which defines a longterm vision and that is driven by entities with charismatic people. It's easier to start with a small set of actors with matching actions. An alternative to enable the cluster is the definition of a territorial brand to identify the region with a particular industry or a group of products. Typically, brands that are designed by local administrations, in many cases do not have any repercussions, many times they are good purposes without transcendence. When the productive and academic sectors are backed and supported by local administrations when defining a brand, it can be very beneficial for the companies, the promotion of investment, marketing of products and especially to the region where they are located.

What does an agglomeration scheme mean from an institutional point of view at the Caribbean Region 1 level? Are there basic input conditions for configuring a cluster based on innovation and cooperation for the industry of shipyards? It is a fact that for the Caribbean region, it is a priority to orient the scientific, technological and institutional support capacities according to the needs defined by the initiatives of the productive and competitive commitments made at the regional level, in this case given the increasing importance of the naval, maritime and fluvial industry of the Caribbean region and of actors such as the universities and Cotecmar that have shown consistency and vision by supporting initiatives of regional technological development .

The maritime and fluvial industry in the Caribbean region and, in general, the actors related to maritime activities and the different aquatic waterways, are characterized by being immersed in strong global competition demanded by the international trade in goods (cargo) and services (nautical tourism in its different expressions). A communal bet made through a Technological Platform for the Shipyard Sector Cluster - PTCSA- focused on the priorities required by maritime activity today, from a medium-and long-term perspective, must provide competitive tools and the basis of knowhow, enabling all actors to successfully respond to the challenges of globalization.

The set of actions identified above to boost a cluster of the shipyard sector in the Caribbean region requires the definition of the development of technologies in line with the needs of the productive sector in order to improve productivity and regional competitiveness. Basically what happens is that, given the central importance of technology 
as an instrument to achieve competitiveness, it is necessary to define actions in terms of the science and technology policy for and depending on regional development (Ondategui 1999) ${ }^{14}$ that is focused on improving the links between actors, collaborative capacities and the development of technologies that promote innovation of the Naval, Maritime and fluvial industries In this way the cluster initiative of the shipyard sector of the Caribbean region begins by defining a number of stylized facts that leads it to be profiled as an alternative of regional innovation, based on relationships and of Knowledge management, among which the following are considered:

- To define and develop a Technology Platform for the shipyard sector cluster - PTCSA of the Caribbean region defined with time limits. It is part of a Planning process, defined by a strategy with medium and long term vision, supported by research and technological development programs, responding to business needs characterized by their exposure to the global market and with the concurrence of many companies of different types of technologies.

- To design a specialized services platform for the promotion of cluster innovation. Considered a Business model, whereby from a technological productive limitation a technological solution can be offered. This model should be based on the current capacities of the groups and research centers belonging to the regional universities and COTECMAR. Therefore, services must be offered ranging from formulation, management, research, technology transfer at different levels and areas of knowledge, supported in research and development processes.

- Promote network knowledge management. The cluster must be part of a network of public and private institutions belonging to the Regional System of Science, Technology and Innovation that act as managers of projects, providing

$14 \quad$ Ondategui, Julius Caesar. Innovation and Regional development networks in the Northwest Peninsular. Regional Studies Magazine, Universidad Complutense de Madrid. Madrid Spain 1999 novel instruments to guide and strengthen research and technological development processes, and whose fundamental purpose is its performance with the productive sector.

- To promote a Regional Innovation model. The promoting of regional innovation should take advantage of recognizing the cluster of the shipyard sector of the Caribbean region, starting from the definition of a brand. The model should perform activities of animation, articulation, cooperation between the different actors within the cluster and related actors at the local, national and international levels, to develop programs and projects to support the technological conditions and characteristics of the region itself

- Provide innovative means to the productive sector. The Caribbean region must develop infrastructure to improve the scientific and technological capacities to promote the scientific spirit, the ability innovate and entrepreneurship. The internal evidence shows the creation of Science and Technology Parks, technological development centers, research centers, the network of laboratories, among others, that support the generation of new products, but that especially count on business support services for the promotion of innovation

- To promote the investment of public-private resources in R\&D. Have a Scheme of PublicPrivate funding for the development of the activities of applied research as a manifestation of the commitment of the different public and private actors in advancing the technological development and knowledge management.

In a general manner and to advance the development of the activities, the Cluster actors, within the framework of the PTP, should continue to guide their actions through an institutional structure with scientific and technological capacities, articulation and coordination schemes. Notwithstanding the above, and taking advantage of the trajectory of Cotecmar, a Technology Platform for the Shipyard Sector cluster - PTCSA- should be proposed that includes a common agenda to strengthen and 
promote innovation ${ }^{15}$. To do this, the following is required: i) To define a vision of the shipyard sector in the medium and long term and its valuation in a consensual way. ii) Determine quantifiable and measurable objectives. iii) Define actions to be undertaken to achieve these objectives. iv) Determine the priority activities of $\mathrm{R}+\mathrm{D}+\mathrm{I}$ by the group of stakeholders in the shipyards sector and related industries. v) Define the objectives to be achieved by mobilizing the necessary human and financial resources.

In this way, the cluster created is presented as a new paradigm in the ways of producing and organizing according to regional knowledge. The probability of achieving this will be greater for those who understand and adopt creatively and intelligently the notion of technological innovation as a guide to competitiveness, which has generated in recent years a change in the business culture, with the deliberate and systematic incorporation of technological management as a dominant dimension in the modern management of organizations.

As part of the development of the Technology Platform that should support the cluster of the shipyards sector, it is considered to work in some specific areas for each care sector, supported by the extensive human, scientific and infrastructural capital that facilitates the linkage of investigative processes to the needs of the different actors and producers of the maritime and naval industry of the Caribbean region. In this way, the orientation for the construction of the Technology Platform for the shipyard Sector cluster - PTCSA as an alliance for innovation, should guide the productive development that supports the maritime and fluvial industry in the Caribbean region.

\section{By way of conclusion a final reflection}

Today, science, technology and innovation are strategic factors that explain the generation of value added and competitiveness of countries, regions and companies. In this new scenario, the generating factor of wealth and human development, is based on the capacity of people and companies to develop products, goods, services and processes in general that are innovative, and that allow to practical applications to be developed based on the generation of knowledge derived from the processes of research, technological development and innovation.

The probability of having a maritime and naval industry as a world class sector world from the impulse of the development of the cluster of the shipyard sector, exposed to globalization necessarily must define a consensual innovation strategy that is animated by local actors of the Caribbean region. The proposal, such as the development of the experiences of European Technological platforms such as the Spanish Maritime Technological Platform 2020 "puts the agents in contact, brings together and facilitates the generation of relationships and multi-directional inter-actions to use the knowledge generated from research projects".

Therefore, in order to reach a consensus on the direction of strategies supported in the development of research projects the development of new necessary knowledge should be promoted to ensure compliance with the Regional Competitiveness Plan of Cartagena and Bolivar 2008 - 2032. The demand for effectiveness implies encouraging collaboration and cooperation in the $\mathrm{R}+\mathrm{D}$ $+\mathrm{i}$ actions of all the agents involved, as well as, significantly increasing the financial and human resources devoted to such activities, from both private origin and public sources.

In practice, the above involves action from all the areas of policy: national, departmental and local, science, technology, and innovation; and from the partner entities, the actors in the productive sector, thinking about the regional development that allows interdependence relationships to be multiplied, and the fundamental establishing of stable information channels and creation of collaborative opportunities around specific problems.

15 Developed from the Spanish Maritime Technological Platform 2020. 


\section{References}

CHESBROUGH (2003) The era of open innovation. Spring MIT Sloan Management Review

Regional Competitiveness Commission of Cartagena and Bolívar. (2010). Regional competitiveness Plan of Cartagena and Bolívar $2008-2032$.

COMPETITIVENESS (2015), Nautical Cartagena: Competitive route of the nautical industry

NATIONAL PLANNING DEPARTMENT (2008) Conpes Document 3527, National Competitiveness and productivity policy, Bogotá June 2008.

NATIONAL PLANNING DEPARTMENT (2009). National policy on science, technology and innovation. Conpes Document No. 3582. Bogota, April 2009.

FREEMAN C AND LUC SOETE (1997), National System of Innovation. The economics of industrial Innovation Third Edition - The MIT Press

INNOVAMAR (2005), Technological Institute Foundation for the development of Marine industries, Spanish Maritime Technological Platform, Vision 2020

Innovation and technology transfer in Europe (2005), More research and innovation. Investing for growth: a common approach. European Commission, Brussels Belgium 1995

INNOVACIÓN EUROPEA. Different IRC newsletters. European Commission, Brussels 2006 and 2007
LUNDVALL B. (2005). National Innovation Systems, Analytical Concept and Development Tool. Paper presented at the DRUIDconference in Copenhagen June 27- June 29, 2005.

LUNDVALL, B (1998)., Innovation as an interactive process: from user-producer interaction to the national system of innovation, In Doses, $\mathrm{g}$. Et al. Eds., Technical Change And Economic Theory, Printer publishers, London y New York, 1988.

METCALFE, J. S. (1995). The economic foundations of technology policy: equilibrium and evolutionary perspectives. In P. Stoneman (Ed.), Handbook of the Economics of Innovations and Technological Change. Oxford: Blackwell Publishers.

ONDATEGUI, J.C., (1999) Innovation and regional development networks in the Northwest Peninsular. Regional Studies Magazine, Universidad Complutense de Madrid. Madrid Spain.

PÉREZ, C., (1991) New technological pattern and higher education: an approximation from the company. Published in López Ospina, ed., Scientific and technological challenges, Vol. 3, pp. 23-49, Unesco, Caracas.

WILLIANSON OR AND SIGNEY G. WINTER. (1996) The nature of the company. Origin, evolution and development. Economic Culture Fund. Mexico. 